\title{
El papel del asociacionismo en la integración sociopolítica de las personas migrantes de origen subsahariano. El caso del País Vasco.
}

\section{Maria Giulia Di Carlo}

Universidad de Deusto, Bilbao

<giulia.dicarlo@gmail.com>
EAEn lekututako Sahara azpiko afrikar jatorriko immigranteen elkarteak hartu dira aztergai artikulu honetan, betiere, partaidetzaren eta integrazio soziopolitikoaren alorretan elkarte horien betekizunean egindakoa aztertzen delarik. Sakonki buruturiko 22 elkarrizketa baliatuz, elkarte horietako ordezkarien bidez jakin nahi izan da berauen barneantolaketaren ezaugarriez, funtzionamenduaz, sare-lana eta elkarte horietan burututako ekintza politikoaz; eta, faktore horien guztien berri izanik, ezagutu nahi izan da elkarte horien eragina kolektiboaren integrazio soziopolitikoaren baliabide gisara.

\section{GAKO-HITZAK:}

asoziazionismoa, integrazio soziopolitikoa, partaidetza, Afrikako migrazioak, Euskal Autonomia Erkidegoa.
Este artículo estudia las asociaciones de personas migrantes de origen subsahariano en el País Vasco, analizando el papel que estas entidades desempeñan en la participación y la integración sociopolítica del citado colectivo. A través de 22 entrevistas en profundidad con representantes de asociaciones, se indaga en las características organizativas, el funcionamiento, el trabajo en red y la acción política de estas asociaciones, como factores que pueden influir en el papel que desempeñan en la integración sociopolítica del colectivo que agrupan.

\section{Palabras Clave:}

asociacionismo, integración sociopolítica, participación, migraciones africanas, País Vasco.

${ }^{1}$ Este artículo se inscribe en el marco de una tesis doctoral titulada "El papel del asociacionismo en la integración social de las personas migrantes de origen subsahariano: transnacionalismo, participación y co-desarrollo. El caso del País Vasco y de Sicilia”, y que está financiada por una beca de Formación de Personal Investigador del Dpto. de Educación del Gobierno Vasco. El trabajo presenta parte de los resultados provisionales de dicha investigación, aún en curso. 


\section{Introducción}

A lo largo de la última década, en la Comunidad Autónoma Vasca se ha producido un aumento progresivo de la llegada de población de origen extranjero, sobre todo entre 2005 y 2009. En la actualidad, la población de origen extranjero en el País Vasco representa el 6,4\% de la población total (Ikuspegi, 2010). El rápido crecimiento de la población extranjera desde 1998 hasta hoy y la variación en la tipología de las migraciones en estos últimos diez años, con el aumento de la población migrante de origen extranjero respecto a la de origen nacional, han generado cambios estructurales que obligan a pensar en la gestión adecuada de las que ya se presentan como sociedades multiculturales, y, por lo tanto, en el desarrollo de procesos conformes a la integración social y la convivencia. La participación de las personas migrantes en el ámbito público, especialmente en aquellos espacios de toma de decisión que se encargan de los procesos de convivencia, resulta fundamental para lograr su integración efectiva. La participación ciudadana es una condición indispensable para que las sociedades en que vivimos se constituyan en verdaderos espacios democráticos.

En este sentido, las asociaciones conformadas por personas de origen subsahariano pueden actuar como agentes sociales que permitan a estas personas hacerse oír, proponer y participar en el proceso de elaboración de políticas públicas, bien sobre aspectos relacionados con la migración, bien sobre otros que afectan a su vida cotidiana y a la sociedad en la que viven. El colectivo de origen subsahariano no tiene ningún derecho político formal reconocido en el País Vasco (ni en España); por lo tanto, debe reconocerse la particular relevancia de sus asociaciones, que pueden funcionar como verdaderos canales de participación de estas personas en el sistema político democrático y en la vida pública del país. Asociaciones fuertes y bien estructuradas podrían representar los instrumentos para reforzar el capital social del grupo y de las personas que lo constituyen, favoreciendo, en última instancia, la participación política y su acceso al voto.

Sin embargo, existen algunas limitaciones para hacer realidad ese objetivo. El derecho al voto de las personas de origen extranjero que residen en España se concede exclusivamente por tratado o por ley, atendiendo a criterios de reciprocidad con terceros países, lo que excluye a este grupo de personas y genera comunidades con derechos políticos diferentes. Esta circunstancia refuerza el surgimiento de cauces de participación política alternativos y provoca una gradación en el efecto real del voto que puede ejercerse: desde el que se deposita en las elecciones de órganos consultivos de representatividad ad hoc, hasta el que se da de manera activa o pasiva en las elecciones administrativas. Este trato discriminatorio en nada contribuye al objetivo de la plena integración de las personas de origen subsahariano.
Es en este contexto en el que se reconoce la particular relevancia de las asociaciones, que pueden funcionar como canales de participación en el sistema político democrático y en la vida pública del país de destino (Fennema y Tillie, 2001). De hecho, estas asociaciones a menudo se constituyen 'desde abajo', es decir, para responder a necesidades y exigencias de los grupos que se reconocen en alguna identidad común, como la étnico-nacional o la religiosa. Lejos de actuar en un sistema vacío, estas asociaciones se encuadran en contextos en los que se dan determinadas reglas y en los que operan unas instituciones que pueden contribuir, en mayor o menor medida, a dar forma a sus demandas y reivindicaciones. Las asociaciones se enfrentan siempre a nuevas realidades, nuevas reglas, instituciones y organizaciones ya presentes en el territorio de destino, por lo que desempeñan la importante función de socialización de las personas en la esfera de la participación cívicopolítica, premisa fundamental para la integración. En consecuencia, el asociacionismo de estas personas estará más consolidado allí donde las políticas sean más favorables a la apertura de los diferentes grupos, es decir, allí donde se den políticas que aseguren no sólo el reconocimiento simbólico de estos grupos, sino también el material (Bloemraad, 2005: 866).

\section{Las asociaciones pueden funcionar como canales de participación en el sistema político democrático}

Según esta idea, las asociaciones fuertes y bien estructuradas representarán instrumentos importantes para reforzar el capital social del grupo y de los individuos que las constituyen, favoreciendo en última instancia la participación política y el acceso al voto. Por lo tanto, la agencia colectiva de las personas migrantes adquiere mayor importancia cuando el marco legal del contexto de recepción restringe sus derechos de ciudadanía, en este caso, los derechos políticos. Cuanto más difíciles y restrictivos sean los requisitos de acceso a la ciudadanía, más confinado estará el colectivo migrante a las formas de participación política no convencional de naturaleza colectiva -protestas, huelgas, presión mediática- (Martiniello, 2005: 16).

Aunque el asociacionismo extranjero constituye una práctica habitual en todos los países europeos, tanto en aquellos países receptores de nueva inmigración como en aquellos donde este fenómeno revista mayor antigüedad, su consistencia y relevancia puede variar en función de los contextos nacionales y locales. En el caso de España, y particularmente en el País Vasco, el asociacionismo de la población migrante de origen subsahariano empezó a configurarse alrededor de 2000 , sobre todo en las capitales de los tres territorios históricos: Bilbao, VitoriaGasteiz y Donostia-San Sebastián. 


\section{Participación como vía de integración: los derechos de las personas extranjeras en la sociedad de acogida}

La integración puede definirse como "el proceso a través del cual la persona se convierte en una parte aceptada de la sociedad" (Martinello y Penninx, 2006: 127). En términos generales, una persona es parte de la sociedad -está integrada- cuando puede ejercer plenamente sus derechos de ciudadanía. Los diferentes planos en los que se produce la integración (social, económico, cultural, político) equivalen a las tres dimensiones que tradicionalmente se han distinguido en el concepto de ciudadanía: la política, la socioeconómica y la cultural. En sentido etimológico y sociológico, integración significa formar parte de la sociedad en que se vive, y muchas veces esto no es válido para los migrantes. El concepto de integración social comprende muchos sectores de la vida de un migrante: el trabajo, la vivienda y la vida social.

En el presente trabajo se considera la dimensión cívico-política de la ciudadanía. Por lo tanto, se utiliza la noción de integración política multicultural empleada, por ejemplo, en un estudio realizado en Madrid sobre asociaciones de migrantes (González Ferrer y Morales, 2006). Las autoras de dicho estudio afirman que:

El modelo deseable de integración es aquel que combina un acceso a la ciudadanía exclusivamente basado en la concesión de derechos tras cumplirse una serie de requisitos de tipo universalista, y la reserva de un papel comprometido a los ciudadanos en el proceso democrático (pág. 4).

Es decir, la integración política del colectivo migrante exige el reconocimiento formal de sus derechos políticos como ciudadanos, a través del sufragio activo y pasivo, así como del derecho a asociarse como el resto de la población; y por otro lado, tiene que garantizar su participación activa en el espacio público, con el fin de trasladar sus ideas, proyectos y necesidades a los procesos de toma de decisión. En este sentido, las asociaciones de migrantes, como organizaciones de la sociedad civil, pueden servir para canalizar demandas, intereses y sugerencias del colectivo a las instituciones públicas y a la sociedad en general. De hecho, la agencia colectiva de las personas migrantes adquiere mayor importancia cuando el marco legal del contexto de recepción restringe sus derechos de ciudadanía, en este caso, los derechos políticos. En función de cuáles sean las normas de acceso a la ciudadanía y de pérdida de ésta, las personas tendrán mayores o menores oportunidades de participar en la vida pública formal. Si el acceso a la ciudadanía se ve restringido, el colectivo migrante se verá empujado a utilizar formas de participación política no convencionales.

Según González y Morales (op. cit.), el concepto de integración política multicultural aplicado a la ciudadanía en el plano individual puede trasladarse al plano organizativo del colectivo migrante. Por lo tanto, podemos ajustar este concepto al caso específico de las asociaciones de migrantes subsaharianos. Con respecto a los derechos de acceso a la ciudadanía en el plano individual, se plantea, haciendo referencia al reconocimiento formal de las asociaciones, el reconocimiento de un estatus favorable de acceso al proceso de toma de decisiones a través de la inclusión en algún registro formal de la administración pública y de su reconocimiento legal, así como su inclusión formal en mecanismos de decisión y consultivos, tales como consejos, foros, mesas de diálogo, etc.

Sin embargo, como se ha mencionado anteriormente, la participación efectiva de la población migrante en el espacio público es condición imprescindible para conseguir una integración efectiva. De ahí que sea también necesario analizar cómo y en qué medida las asociaciones de migrantes están influyendo y participando activamente en los procesos de toma de decisiones sobre las cuestiones que afectan específicamente al colectivo, pero también, sobre los que interesan al desarrollo de su vida cotidiana y a la convivencia en la sociedad receptora. Esta participación efectiva de las asociaciones puede estudiarse a través de la información sobre el tipo de actividades políticas que realizan, de sus contactos con organizaciones políticas y de la forma en que participan en los mecanismos de toma de decisiones a los que han tenido acceso. Ahora bien, debe tenerse en cuenta que la movilización y participación política de las asociaciones dependerá de varios factores, entre los que pueden destacarse las características sociodemográficas de las personas miembros (contexto socioculturales de origen, nivel socioeconómico, roles de género), las individuales y su capital social interno y externo, junto a la estructura de oportunidades políticas que ofrecen las sociedades de origen y destino.

Este artículo sobre la realidad asociativa migrante subsahariana centrará su atención en los factores que están influyendo en el capital social externo de las asociaciones estudiadas. En general, el capital social puede definirse como el conjunto de relaciones que se establecen y desarrollan entre los diversos actores de la sociedad civil, con el fin de conseguir unos objetivos concretos y colectivos (vínculos de mutua confianza, de intercambio de información y de otros recursos). La noción de capital social aquí utilizada se basa en el enfoque empleado por Fenemma y Tillie (2001), quienes distinguen entre:

- Capital social étnico, que se refiere a los vínculos que se establecen en el ámbito interno de las asociaciones y entre asociaciones de migrantes.

- Capital social no étnico, que se refiere a las conexiones externas de las asociaciones con otras organizaciones y grupos heterogéneos.

Algunos estudios realizados en diferentes áreas de Europa confirman la relación existente entre partici- 
pación política, por un lado, y capital social del colectivo migrante y sus asociaciones, por otro (Fennema y Tillie, 2001; Berger, Galonska y Koopmans, 2004; Tillie y Slijper, 2006). Las personas migrantes, como las autóctonas, tienden a crear organizaciones en los lugares donde se asientan y desarrollan su vida cotidiana. Estas organizaciones pueden servir, por lo tanto, como espacios de encuentro y apoyo mutuo, y también como un medio para trasladar sus demandas, necesidades e intereses a las instituciones públicas y a la sociedad en general.

En este trabajo se toma en consideración al colectivo de África Subsahariana. Esta comunidad, asentada en España, no posee ningún derecho político formal, ni a escala estatal ni autonómica. Por lo dicho, los espacios de participación política informal, como las asociaciones que estas personas crean, pueden ser lugares donde entrenar prácticas democráticas aplicables tanto a la sociedad de origen como a la de destino.

Las instituciones públicas siguen tratando la migración como un fenómeno coyuntural y la asocian a menudo al ámbito económico-laboral. Esto ha influido en la menor atención prestada a la dimensión cívico-política de la integración de la población migrante. Sin embargo, en la actualidad las personas migrantes representan una realidad consolidada en nuestras sociedades. El asentamiento a largo plazo conlleva la necesidad de desarrollar el proyecto migratorio en todos los ámbitos de la vida -social, económico, cultural y político-, y plantea el reto compartido de generar un marco de convivencia adecuado para el desarrollo efectivo de sus proyectos vitales. La participación en el espacio público, es decir, en aquellos espacios de toma de decisión de la sociedad en que viven, es un aspecto crucial para la integración efectiva de las personas migrantes. El reconocimiento de las personas extranjeras como ciudadanas de pleno derecho en nuestras sociedades es un paso fundamental para la integración sociopolítica de aquéllas.

En este sentido, las asociaciones de personas migrantes se consideran, en origen y destino, como canales abiertos, a través de los cuales estas personas puedan tramitar demandas y propuestas a las instituciones públicas en los dos lugares 'a los que pertenecen', incluyendo aquellas acciones de incidencia política que puedan fomentar procesos de cambios democráticos en los países de origen, y procesos de adquisición de derechos en los países de residencia.

\section{Las migraciones africanas de origen subsahariano en el País Vasco y sus asociaciones}

Los movimientos migratorios son parte constitutiva de la historia más reciente del País Vasco. Tanto la emigración como la inmigración de personas han ido conformando la sociedad vasca actual. Sin embargo, en cuanto a la llegada de personas de origen extranjero a la CAV, es a partir de 1998 cuando ese flujo se hace más intenso. Aunque las migraciones no son un fenómeno nuevo, sí lo es el tipo de migración que se configura desde ese año, y que ha hecho que el País Vasco pase de ser una región receptora de personas migrantes internas a una región receptora de migraciones extranjeras, lo que ha provocado cambios sociales notables (diversidad racial, cultural, lingüística y religiosa).

Dentro de los colectivos presentes en las tres provincias vascas, el de las personas de origen subsahariano no destaca entre los más numerosos, aunque en los últimos años ha habido un incremento importante de las personas de origen subsahariano en todo el territorio vasco. La mayoría de los migrantes subsaharianos llegaron a la CAV entre 2000 y 2004 , sobre todo por motivos económicos, en búsqueda de un trabajo o por reagrupaciones familiares ${ }^{2}$ (Moreno, 2008). Bizkaia, en 2010, acogía el 64,16\% de las personas migrantes de origen subsahariano asentadas en la CAV, mientras que Gipuzkoa albergaba al $22,47 \%$, y Álava, al 13,37\%.

Hoy día, en el País Vasco viven 8.437 personas de origen subsahariano, es decir, que la población subsahariana representa el 6,06\% del total de la población extranjera en la CAV. El mayor crecimiento de la población africana de origen subsahariano se registró entre 2004 , cuando se contaba con la presencia de 3.592 personas de este colectivo, y 2010, año en que ascendía a 8.437 personas (Gráfico 1). Por países, Senegal aporta 2.192 personas, es decir, el $25,98 \%$ de las procedentes del africana subsahariana. Le siguen Nigeria, con 1.221 personas, y Guinea Ecuatorial, con 876 personas. Otras presencias importantes son las del colectivo mauritano, el maliense y el del ghanés. 


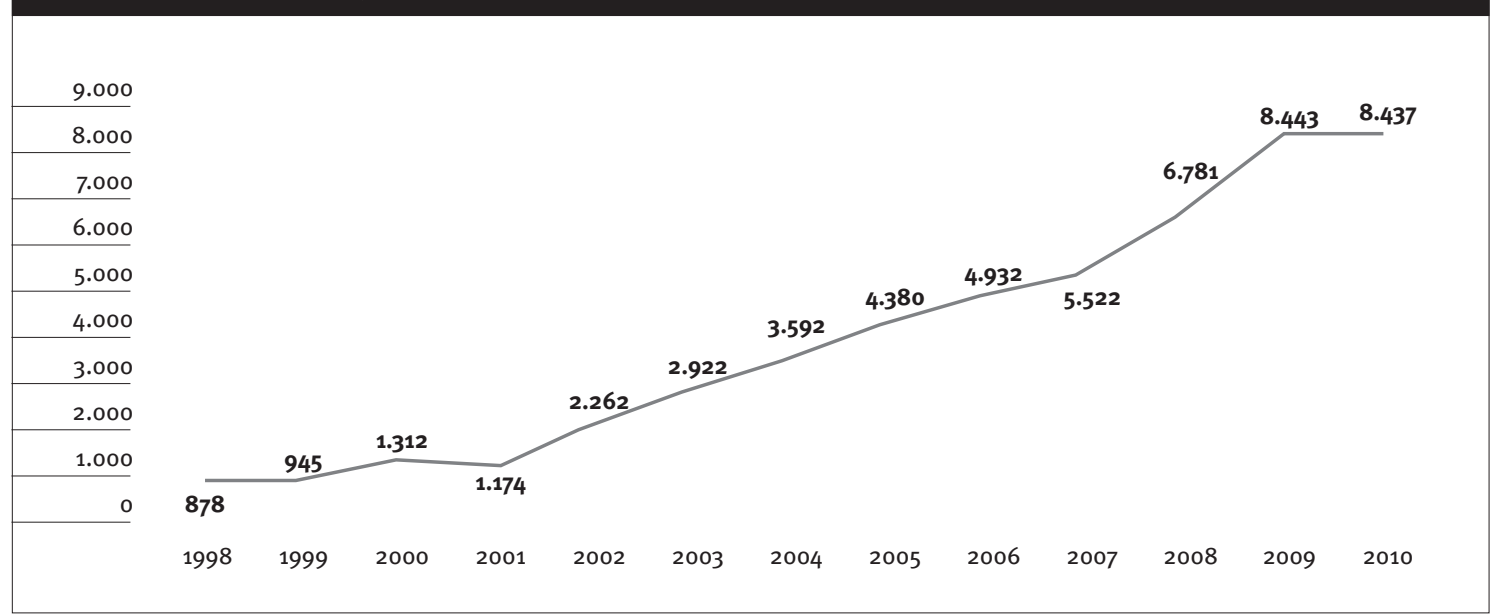

Fuente: Elaboración propia.

Tabla 1. Principales países de origen de la inmigración subsahariana en Euskadi (2010)

\begin{tabular}{l|c|c}
\hline Países de origen & N & $\begin{array}{c}\text { \% sobre la } \\
\text { población } \\
\text { extranjera total }\end{array}$ \\
\hline Senegal & 2.192 & 1,57 \\
\hline Nigeria & 1.221 & 0,88 \\
\hline Guinea Ecuatorial & 876 & 0,63 \\
\hline Mauritania & 581 & 0,42 \\
\hline Mali & 572 & 0,41 \\
\hline Ghana & 568 & 0,41 \\
\hline Camerún & 493 & 0,35 \\
\hline República Democrática del & 323 & 0,23 \\
\hline Congo & 1.002 & 0,72 \\
\hline Angola & 8.437 & 0,23 \\
\hline Guinea-Bissau & 322 & 0,21 \\
\hline Resto de países & 287 & \\
\hline
\end{tabular}

Fuente: Elaboración propia a partir de datos de Ikuspegi.

En el conjunto de la CAV, se encontraron un total de 47 asociaciones compuestas por personas de origen subsahariano. De éstas, 43 están registradas formalmente en los registros municipales y autonómicos, y hay cuatro grupos informales, es decir, que todavía no se han constituido formalmente, pero que funcionan de facto como asociaciones, a todos los efectos. De las 43 formales, 30 están ubicadas en Bizkaia, 10 en Álava y tres en Gipuzkoa. Los grupos informales se ubican en Bilbao (3) y Vitoria-Gasteiz (1).

Como hemos visto, las personas que proceden de África Subsahariana no destacan por una presencia numerosa en el País Vasco. Por el contrario, las asociaciones que éstas impulsan resultan ser las más abundantes de Euskadi entre las formadas por personas migrantes (Unzueta y Di Carlo, 2010; Di Carlo, Ruiz Aranguren y Ruiz Balzola, 2011). En dos estudios recientes editados por Bakeaz sobre las asociaciones de personas migrantes en las tres provincias vascas, los resultados arrojan un predominio de las asociaciones de origen africano subsahariano en Bizkaia y Álava: en el primer caso, el 35,29\% (30 de 85) de las asociaciones censadas están compuestas por personas de origen subsahariano; en el segundo, alcanzan el 37,5\% (10 de 24). Finalmente, en Gipuzkoa estas asociaciones representan el 9,68\% (3 de 31) de todas las censadas.

Estos datos contrastan con la distribución de la población extranjera por nacionalidad en la CAV, puesto que dominan las personas latinoamericanas, con un 48,14\%. Dicho de otra manera, la densidad asociativa de la población africana es sustancialmente mayor $(5,6 \%)^{3}$ que la de la población de otros orígenes.

Las asociaciones censadas hasta hoy se concentran principalmente en Bilbao (10), Vitoria-Gasteiz (10) y Durango (4), de acuerdo con los datos estadísticos sobre la población extranjera en esas tres ciudades vascas. Otros municipios que cuentan con asociaciones de personas de origen subsahariano son Markina (1), Ondarroa (1), Zarautz (1), Donostia-San Sebastián (1) y Hondarribia (1).

Respecto a la nacionalidad de origen de las personas miembros de estas asociaciones, en la Tabla 2 se observa que los países que registran un mayor número de asociaciones son Senegal (13), Camerún (5), Nigeria (4) y Ghana (3). Cabe subrayar la presencia de 11 asociaciones compuestas por personas de países subsaharianos de la misma aérea geográfica.

3 Elaboración propia. 
Dentro del resto de asociaciones, se encontró una gran variedad de países de origen (nacionalidades), entre ellos, Guinea, Guinea Bissau, Guinea Ecuatorial, Angola y Mali.

Tabla 2. Origen nacional de las asociaciones subsaharianas en el País Vasco (2010-2011)

\begin{tabular}{l|c|c}
\hline País de origen & N & $\%$ \\
\hline Senegal & 13 & 27,66 \\
\hline $\begin{array}{l}\text { Diferentes países } \\
\text { subsaharianos }\end{array}$ & 11 & 23,40 \\
\hline Camerún & 5 & 10,64 \\
\hline Nigeria & 4 & 8,51 \\
\hline Ghana & 3 & 6,38 \\
\hline Resto de países & 11 & 23,40 \\
\hline Total & 47 & 100,00 \\
\hline
\end{tabular}

Fuente: Elaboración propia.

En el caso de las asociaciones de personas de origen senegalés, que destacan por la mayor densidad asociativa en la CAV -conforme a su mayor presencia demográfica-, se encontraron asociaciones constituidas por personas de diferentes áreas geográficas (sur/norte) y religiones (musulmanes/católicos). Dentro del colectivo nigeriano, hay asociaciones formadas por personas de diferentes regiones geográficas de Nigeria. Por último, entre las asociaciones de personas de Guinea Conakry se encontraron asociaciones que agrupan a personas según su etnia (poulares, malinkes). A raíz de los resultados cuantitativos obtenidos, cabe decir, pues, que son asociaciones muy variadas y que, dentro de una misma nacionalidad, las personas pueden agruparse por etnia o religión. Otra de las características generales de las 43 asociaciones formales analizadas es su reciente creación, comprendida mayoritariamente entre cuatro y cinco años de antigüedad.

Las asociaciones de migrantes normalmente suelen dedicarse a más de un área de trabajo, lo que también sucede entre las compuestas por el colectivo migrante originario del África Subsahariana. Las áreas de intervención más desarrolladas en estas últimas son la sociocultural -en la que se incluyen aquellas actividades destinadas a la promoción de la cultura de origen- y la de intervención a favor del migrante. Otras áreas de trabajo destacables son las de cooperación y co-desarrollo, deporte y prácticas religiosas. En el área sociocultural intervienen más de la mitad de las asociaciones (51,06\%). Cabe mencionar que, dentro de las asociaciones registradas formalmente, ninguna se dedica específicamente a promover la participación sociopolítica en la sociedad de destino, mientras que dentro de los grupos informales, dos destacan por la labor que vienen desempeñando a favor de los derechos de las personas que los componen en la sociedad de acogida, a través de actividades de reivindicación y de promoción del voto en origen.

\section{El asociacionismo de origen subsahariano en el País Vasco: características estructurales, trabajo en red y acción política}

En lo expuesto anteriormente, se ha querido contextualizar el fenómeno del asociacionismo migrante de origen subsahariano en la CAV, para acercarnos, a continuación, a los resultados de las entrevistas en profundidad realizadas con las asociaciones (22 en total) y así marcar algunas reflexiones que pueden ayudarnos a comprender el papel que están desempeñando como sujeto sociopolítico.

Por lo que se refiere a las características organizativas, un volumen importante de asociaciones contactadas orienta principalmente sus actividades a facilitar la integración sociolaboral de las personas a quienes se dirigen, $y$, en menor medida, a facilitar la integración política. Una amplia mayoría presenta, por esta misma razón, una estructura asociativa de servicios, mientras que algunas combinan una estructura de tipo reivindicativo con otra de servicios. El hecho de que estas asociaciones dediquen gran parte de su trabajo a la prestación de servicios, como respuesta a la demanda y las necesidades del colectivo migrante, conlleva que muchas personas acudan a ellas en primer lugar como demandantes de servicios, y éste parece ser uno de los factores que más está influyendo en la capacidad de movilización interna de las asociaciones. De hecho, todas las personas entrevistadas han afirmado que uno de los retos más difíciles a los que se enfrentan cada día es el de garantizar la participación activa de sus miembros. Además, la situación vital de las personas migrantes y los conflictos de liderazgo y de gestión asociativa aparecen como problemas fundamentales para mantener una base social sólida, aunque la disponibilidad de recursos influye también.

En general, todas las asociaciones han declarado tener dificultades para garantizar los recursos físicos y humanos que requiere el mantenimiento de toda estructura asociativa, aunque varíen en intensidad de unas a otras. De hecho, todas las asociaciones dependen del voluntariado para su funcionamiento y una gran mayoría carecen de un lugar de reunión propio y estable. Esto está relacionado, evidentemente, con las vías de financiación a las que acceden y con las posibilidades reales que encuentran para garantizar los recursos económicos necesarios para su funcionamiento.

A pesar de que algunas han conseguido acceder a subvenciones públicas, todas experimentan, o han experimentado, dificultades comunes de acceso, como el alto nivel de exigencia burocráticoadministrativa en relación con el nivel de formación y experiencia técnica de los miembros, o la resolución tardía de las subvenciones, en el caso de algunas administraciones públicas. La postura mayoritaria pide que las instituciones públicas se comprometan más activamente en el fortalecimiento del asociacio- 
nismo migrante, y se percibe un recelo generalizado hacia los recortes de presupuesto público que se han registrado en el actual contexto de crisis económica. En concreto, se comentan los temores que estos recortes puedan influir negativamente en las políticas de apoyo y promoción del asociacionismo entre el colectivo migrante.

\section{Los vínculos que se} establecen con las asociaciones de migrantes se dan mayoritariamente para crear redes de trabajo o para organizar actividades culturales puntuales

El análisis de las relaciones que las asociaciones establecen con otras (redes), bien sean de migrantes o de no migrantes, muestra que, por lo general, las asociaciones contactadas están predispuestas al contacto y la colaboración con otras organizaciones, tanto si son de migrantes como de autóctonos. Dicha apertura se observa, en mayor medida, hacia aquellas asociaciones que comparten elementos comunes, como el origen nacional de una misma zona geográfica o algunos rasgos culturales. Los vínculos que se establecen con las asociaciones de migrantes se dan mayoritariamente para crear redes de trabajo o para organizar actividades culturales puntuales. La densidad de las redes con otras organizaciones de 'no migrantes' es baja y, en la mayoría de los casos, se tiende a privilegiar los contactos con organizaciones de apoyo que puedan resultar útiles para solventar algunas problemáticas del día a día de las personas que acuden a las asociaciones.

Por lo tanto, las actividades de tipo cultural y las de prestación de servicios son las que más contribuyen al acercamiento, el contacto y la colaboración de unas asociaciones con otras. Sin embargo, estos lazos de colaboración centrados en el aspecto sociocultural no son los únicos que se dan entre las diferentes asociaciones, y destaca la importancia que tiene, para la mayoría de las asociaciones, la relación constante y continua en el tiempo con organizaciones ubicadas, en los países de origen. Estos vínculos se crean por diferentes razones, entre ellas, la necesidad de llevar a cabo proyectos solidarios o de influir en las políticas exteriores de los países de origen y destino.

Las entrevistas han permitido también averiguar si existen redes organizativas activas en el ámbito de la migración. Son muchas las redes y plataformas identificadas en cada territorio histórico, y muchas también las actividades a que se dedican. Ninguna plataforma/red, sin embargo, ha sido valorada como un nodo de referencia entre las asociaciones de migrantes subsaharianos entrevistadas, si bien debe tenerse en cuenta que la Coordinadora de ONG de Euskadi de Apoyo a Inmigrantes-Harresiak Apurtuz es la que aglutina más asociaciones en toda la CAV y, según se ha comentado en alguna de las entrevistas, está contribuyendo, de alguna forma, a establecer vínculos asociativos más allá de los aspectos socioculturales, actuando como intermediaria con las instituciones públicas para trasladar propuestas, reivindicaciones e intereses del colectivo migrante y sus organizaciones. No obstante, las asociaciones dejan entender que estas redes no parecen aglutinarlas alrededor de unas directrices políticas comunes con el fin de incidir en la participación sociopolítica. El surgimiento de la Federación de Asociaciones de Migrantes Senegaleses del País Vasco en 2010, así como la adhesión de una asociación de guineanos a la Red Haaly Poular ${ }^{4}$, ponen de manifiesto el interés de una parte de estas asociaciones por crear redes que defiendan los intereses de grupos nacionales/ étnicos bien definidos, evitando que sean asumidos o representados por otras organizaciones de apoyo al colectivo migrante, de forma que las sustituyan en los procesos consultivos de las administraciones públicas en materia migratoria, no sólo a escala nacional, sino transnacional. Por otro lado, esto podría significar también unos intereses que pueden generar fracturas dentro del propio colectivo, que probablemente no tiene los mismos objetivos. Esto puede denotar que existen -y se les ha de prestar mayor atención- algunos factores que están dificultando el trabajo en red entre las organizaciones, y por lo tanto, la configuración de un movimiento social con capacidad de acción y propuesta en el ámbito público, y capaz también de influir en los procesos políticos sobre cuestiones que afectan al colectivo y a la sociedad en general. Entre estos factores -algunos de los cuales se han identificado a través del contacto con las asociaciones- tienen que ver con la frágil consolidación interna de muchas asociaciones, que suelen trabajar con personal voluntario y se ven afectadas a menudo por las problemáticas a las que se enfrentan sus miembros, y con la mayor orientación de las ayudas públicas hacia el ámbito cultural.

En cuanto al acceso y la participación en los asuntos públicos de las asociaciones objeto de estudio, así como de las vías que están utilizando para ser escuchadas en sus reivindicaciones y propuestas en materia migratoria, se pueden destacar algunos resultados. En primer lugar, las 43 asociaciones formales han logrado cruzar el umbral de acceso al ámbito público, mediante su formalización e inscripción en los registros de asociaciones municipales y del Gobierno Vasco. Sin embargo, su presencia y participación real se ven muy limitadas, debido a la escasez de canales de participación entre las instituciones de los municipios en los que se ubican. Es decir, por el momento, las oportunidades que

${ }^{4}$ La Red Haaly Poular funciona a escala internacional y aglutina a todas las personas de etnia peul (hablantes de poular) originarias de diferentes países subsaharianos (Guinea, Mali, Senegal principalmente). 
tienen las asociaciones de migrantes de ser consultadas sobre el diseño de políticas públicas en materia migratoria a través de los canales formalizados son muy escasas.

Respecto a los contactos con organizaciones de carácter político, como los partidos y los sindicatos, destacan algunos resultados. La mayoría de las personas entrevistadas afirman que, de momento, no están interesadas en establecer contactos con los partidos políticos, y muchas veces confunden el significado de 'político' con la política en el sentido más amplio del término. Como excepción, dos asociaciones informales se han creado con el claro fin de hacer presión política: una, para proteger los derechos de las personas que integran el grupo, y otra, para influir en las políticas migratorias de los países de origen y destino. Esta reticencia se extiende, en gran parte de las asociaciones, a la relación con los sindicatos, argumentada por la marcada tendencia política de éstos y una insatisfacción frente a las funciones que deberían venir desempeñando. Por lo tanto, parece que estos dos tipos de organizaciones de carácter político tampoco están siendo utilizadas por las asociaciones de migrantes subsaharianos como vías de participación en los asuntos públicos.

En cuanto a la organización de actividades de naturaleza política o a la participación en ellas, se observa que las asociaciones tienden hacia formas reivindicativas y propositivas que no implican una confrontación directa y abierta con las instituciones públicas (manifestaciones, charlas, ruedas de prensa, recogida de firmas). Por lo general, son las entidades de segundo nivel (plataformas y coordinadoras de diferentes ámbitos de actuación) las que movilizan a las asociaciones para su participación en actos de protesta y denuncia, que se centran, principalmente, en cuestiones migratorias (integración y derechos de ciudadanía) y sociales. A menudo, el colectivo de África negra se ve desprotegido y sufre rechazos de varios tipos, por lo que no está motivado a 'dar la cara' de forma directa.

Todo parece indicar que las asociaciones insertas en alguna red o que mantienen algún tipo de relación con éstas son también las que más participan en actividades de naturaleza política. No obstante, el caso de uno de los grupos encontrados pone de manifiesto que no siempre el motor de la acción política de las asociaciones se localiza en las redes y plataformas. Se trata del grupo que trabaja por la defensa de los derechos de las personas que realizan el top manta ${ }^{5}$, y es de destacar que el hecho de no estar constituido formalmente como asociación ni inserto en ninguna de las redes localizadas, no ha sido un obstáculo para su organización y participación en actos públicos de protesta, aunque debe tenerse en cuenta el apoyo continuo que ha recibido por parte de SOS Racismo Bizkaia.

\section{Consideraciones finales}

Concluyendo, podemos afirmar que el grado de participación e integración de las asociaciones de África Subsahariana en el ámbito público, en el proceso político de toma de decisiones sobre aspectos que interesan a las personas migrantes, o sobre otros asuntos que afectan a su vida cotidiana y a la sociedad en la que viven, resulta muy bajo de momento. Además, a día de hoy, las asociaciones subsaharianas no han conseguido conformar un movimiento asociativo migrante que les represente y defienda los intereses del colectivo, al objeto de favorecer su participación pública. Tampoco las instituciones y las organizaciones de segundo nivel han conseguido tener un papel activo en este proceso.

Las asociaciones aquí estudiadas se caracterizan por su juventud, y la escasez de recursos humanos y materiales, que afecta al desarrollo de sus actividades y, muchas veces, a la posibilidad de centrarse en actividades de incidencia política. Los problemas de liderazgo y la escasa base social son factores que también influyen en una "proyección externa exitosa" (Gómez Gil, 2010). El grado de reconocimiento legal de las personas que conforman las asociaciones y su exclusión de la vida política en el país de residencia son algunas de las dificultades mencionadas en las entrevistas para explicar el escaso interés de las personas de origen subsahariano en constituirse como interlocutoras activas en la sociedad vasca. Pero también la mayor orientación de las ayudas públicas al ámbito cultural ha sido mencionada como problema clave a la hora de promover proyectos que se desmarquen del ámbito sociocultural. Las entrevistas dejan entrever claramente que las asociaciones se ven empujadas a dirigir sus actividades al ámbito cultural, debido al tipo de subvenciones promovidas por las instituciones.

Sin embargo, algunas reflexiones realizadas con las personas apuntan hacia un autocuestionamiento, entre parte de estas asociaciones, respecto a la línea de acción principal que debe llevar el colectivo a través de sus asociaciones, en el sentido de que deberían ampliar su horizonte más allá de los ámbitos social y cultural, pensar más allá del propio grupo de origen y crear redes entre todas las personas migrantes. De hecho, las asociaciones comparten dificultades comunes de funcionamiento y participación pública, y coinciden en varias de sus demandas dirigidas a las administraciones públicas.

Las problemáticas mencionadas podrían ser algunos de los factores claves que expliquen la ausencia de un movimiento asociativo fuerte entre la sociedad civil organizada que se trata de estudiar en este trabajo y, por supuesto, algunos de los retos a los cuales se tendrán que enfrentar las dos partes implicadas en el proceso de integración, es decir, las personas migrantes, representadas por las asociaciones, y la sociedad en su conjunto.

\footnotetext{
${ }^{5}$ Venta ambulante a que se dedican las personas migrantes.
} 
BERGER, M.; GALONSKA, C.; y KOOPMANS, R. (2004), "Political integration by a Detour? Ethnic communities and social capital of migrants in Berlin", Journal of Ethnic and Migration Studies, vol. 30, nํㅜ 3, págs. 491-507.

BLOEMRAAD, I. (2005): “The limits of De Tocqueville: How government facilitates organizational capacity in newcomer communities", Journal of Ethnic and Migration Studies, vol. 31, nํㅜ 5 , págs. $865-887$.

DI CARLO, M. G.; RUIZ ARANGUREN, M.; y RUIZ BALZOLA, A. (2011): Estudio-diagnóstico sobre las asociaciones de migrantes de origen extranjero en Álava y Guipúzcoa, Bilbao, Bakeaz.

FENNEMA, M.; TILLIE, J. (2001): "Civic community, political participation and political trust of ethnic groups", Connections, vol. 23, no 2 , págs. 44-59.

GÓMEZ GIL, C. (2010) “El asociacionismo de inmigrantes en el marco de los desafíos de las ONG en las sociedades contemporáneas", en LACOMBA, J.; y FALOMIR, F. (eds.), De las migraciones como problema a las migraciones como oportunidad, Madrid, Catarata, pág. 300.

GONZÁLEZ FERRER, A.; y MORALES, L. (2006): “Las asociaciones de inmigrantes en Madrid. Una nota de investigación sobre su grado de integración política", Revista Española del Tercer Sector, no- 4 [<http:// www.fundacionluisvives.org/rets/4/ articulos/14279/>].
IKUSPEGI (2010), “Población extranjera en la CAPV 2010”, Panorámica de la Inmigración, no- 34 [<http:// www.ikuspegi-inmigracion.net/documentos/ documentos_internos/panoramica34cas.pdf)].

MARTINIELLO, M. (2005): Political Participation, Mobilization and Representation of Immigrants and their Offspring in Europe, serie Willy Brandt Series of Working Papers in International Migration and Ethnic Relations, Malmö, School of International Migration and Ethnic Relations [shdl.handle.net/2043/1495'].

MARTINELLO, M.; y PENNINX, R. (2006): “Procesos de integración y políticas locales: estado de la cuestión y algunas enseñanzas", Revista de Investigaciones Sociológicas, $\mathrm{n}$ 울. págs. 123-156.

MORENO, G.; et al. (2008) Población africana en la CAV 2007, Bilbao, Ikuspegi [<http://www.ikuspegiinmigracion.net/documentos/investigacion/ es/pob_afric_capv_2007.pdf>].

TILLIE, J.; y SLIJPER, B. (2006): “Immigrant political integration and ethnic civic communities in Amsterdam", en BENHABIB, S.; y SHAPIRO, I. (eds.), Identities, Affiliations and Allegiances, Cambridge, Cambridge University Press.

UNZUETA, A.; DI CARLO, M. G. (2010): Estudio-diagnóstico sobre las asociaciones de inmigrantes de origen extranjero en Bizkaia, Bilbao, Bakeaz [khttp://ficheros.bakeaz.org/Informe_final_ asoc_inmigrante.pdf $\rangle$ ]. 